\title{
LV-IL-1
}

\section{0 years of LDLT: Lessons learned}

\author{
Yaman TOKAT*
}

International Liver Center, Turkey

Lecture: Last 20 years there was a great change and improvement in liver transplantation. The greatest improvement was Living Donor Liver Transplantation. Lots of things changed from the beginning, venous outflow with Seg 5-8 drainage, MHV usage in selected cases. Inflow modulation, dual lobe transplants,small for size grafts. Arterial anastomosis techniques with microscope.

Transplant oncology, for HCC, colorectal metastasis and cholangiocarcinoma,was the new challenging area.

This lecture will enlighten the journey of LDLT in the last 20 years. 